\title{
Enhancing Minority Middle School Student Knowledge, Literacy, and Moti- vation in STEM Using Culturally Relevant Contexts
}

\section{Dr. Neil A. Knobloch, Purdue University}

Neil Knobloch is a recognized leader for his scholarship of teaching and learning processes in agricultural sciences to engage and retain students in the STEM career pipeline. His research improves the development of future educators and scientists to engage with K-12 audiences, demonstrates learner-centered teaching strategies to increase student motivation and engagement, and advances intentional and inclusive mentoring of women and minorities in the agricultural STEM disciplines.

\section{Dr. Levon T. Esters, Purdue University}

Dr. Esters serves as the Director of the Mentoring@Purdue (M@P) program which is designed to increase the number of women and URMs receiving advanced post-secondary STEM-based agricultural and life sciences degrees in Purdue University's College of Agriculture. Dr. Esters also serves as a Senior Research Associate at The Penn Center for Minority Serving Institutions (CMSI) at the University of Pennsylvania. Dr. Esters' research focuses broadly on issues of educational equity and access of underrepresented minorities with a concentration on three areas: 1) mentoring of women and underrepresented minority graduate students, 2) STEM career development of racial and ethnic minorities attending HBCUs, and 3) educational and professional mobility of women and underrepresented minority graduate students and faculty.

\section{Prof. Heidi A. Diefes-Dux, Purdue University, West Lafayette (College of Engineering)}

Heidi A. Diefes-Dux is a Professor in the School of Engineering Education at Purdue University. She received her B.S. and M.S. in Food Science from Cornell University and her Ph.D. in Food Process Engineering from the Department of Agricultural and Biological Engineering at Purdue University. She is a member of Purdue's Teaching Academy. Since 1999, she has been a faculty member within the FirstYear Engineering Program, teaching and guiding the design of one of the required first-year engineering courses that engages students in open-ended problem solving and design. Her research focuses on the development, implementation, and assessment of modeling and design activities with authentic engineering contexts. She also focuses on the implementation of standards-based grading and teaching assistant training.

\section{Abeera P. Rehmat, Purdue University}

A Post-doctoral Research Associate at Purdue University.

Quintana M. Clark, Purdue University, West Lafayette

Quintana "Quincy" Clark is a doctoral student in the Department of Agricultural Sciences Education and Communication at Purdue University. Her research focuses on emerging technologies for teaching and learning integrated STEM concepts, model-eliciting activities (MEAs), and the intersection of cognitive load and motivation. Quincy's research also focuses on the impact that STEM intervention/mentoring programs have on enhancing underrepresented students' preparedness for, and persistence in, graduate school.

\section{Ulyssa Hester, Purdue University}

Trinity A. Johnson

Dottie Vollmer, Purdue University

Dottie is a Master's student in the Department of Youth Development and Agricultural Education in the College of Agriculture at Purdue University.

Ms. Elizabeth Morgan Alexander, Purdue University 


\section{Enhancing Minority Middle School Student Knowledge, Literacy, and Motivation in STEM Using Culturally Relevant Contexts}

\section{Introduction}

The purpose of this multi-year National Science Foundation (NSF) project is to design, implement, and evaluate integrated culturally relevant (CR) model-eliciting activities (MEAs) using community issues as the context for learning. To ensure cultural and career relevance the design of the CR MEAs is driven by societal challenges connected to community issues, to engage underrepresented minority (URM) middle school students in CR MEAs that will develop their level of community engagement, career exploration, STEM knowledge, and literacy. Teacher professional development was conducted to prepare teachers to utilize integrated CR MEAs in their classrooms as a context for learning.

This project encompasses four teams: 1) MEA development, 2) community engagement \& mentoring, 3) research, and 4) evaluation. The MEA team develops curriculum that engages students in real-world, community-based problems via CR MEAs in the context of major societal challenges. The community engagement and mentoring team establishes partnerships with community partners to connect students with their community while developing and enhancing their levels of community engagement and career exploration. The research and evaluation teams develop instruments to assess student and teacher experiences throughout the duration of the project. A long-term goal of this project is to increase the number of URM middle school students who are prepared for advanced level secondary STEM courses and postsecondary majors in the STEM fields.

\section{Background}

Science, technology, engineering, and mathematics (STEM) is critical for our future advancement. However, the diverse workforce required to drive STEM advancements forward is lacking. This shortage is due in-part to academic preparation disparities, which appear early in the elementary school years and continue into the 8th grade [1]; national test scores suggest that many U.S. students finish the middle grades underprepared in STEM subjects [1-5]. The National Assessment of Educational Progress finds roughly 75\% of U.S. 8th graders are not proficient in math at the end of 8th grade [2]. Reflecting on the disparity of URMs in the U.S. that enter the STEM fields, fostering success among URM minority students in STEM has never been more important. Thus, it is imperative to find ways to facilitate success in K-12 STEM education among URM students. One way this can be achieved is by connecting curricula and instruction through culturally relevant pedagogies (CRP) as this can facilitate the success of URM students in mathematics and science in $\mathrm{K}-12$ education [6].

\section{Culturally Relevant Pedagogy (CRP)}

Culturally Relevant pedagogy as defined by Ladson-Billing [7] is one that "empowers students intellectually, socially, emotionally, and politically using cultural referents to impart knowledge, skills, and attitudes” [pp. 16-17]. The framework of culturally relevant pedagogy encompasses three tenets: academic achievement, cultural competence, and, sociopolitical consciousness. These tenets can be employed in various contexts with a diverse population through classroom instruction, during teacher education, and as a framework for educational research [7]. Many scholars have highlighted the role of CRP in facilitating the success of URM students in mathematics and science in K-12 education [8-9]. In this study, CRP is an important consideration, because when science and math teachers instruct from a Eurocentric point of view, 
they fail to include an approach that connects curriculum, instruction, and assessment to the experiences, cultures, and traditions of URM students [10-11]. Teachers pursuing CRP will need to understand the sense-making practices of communities, the science-related values that reside in them, and the historical relationship that exists between URM communities and local institutions of education [8]. Research illustrates that incorporating CRP into science and mathematics instruction has a positive impact on African American students [8, 10-11].

\section{Model-Eliciting Activities (MEAs)}

Model-Eliciting Activities (MEAs) are realistic, client-driven problems that are inherently interdisciplinary and require student teams to develop a math model of a client procedure/product for a given problem [12-13]. MEAs facilitate learning by developing students' conceptual understandings and sense making of data in real-world contexts. MEAs are model-eliciting in that they require students to mathematize (e.g., quantify) information in context to develop a math model as a procedure/ product [12]. MEAs are thought-revealing in that they provide student teams an opportunity to self-reflect and provide teachers a window into students' thinking during solution development. Six principles guide the design of MEAs [12]. These design principles require that all MEAs include: 1) model construction - a math model of a procedure/product, 2) realistic context - an authentic STEM related problem, 3) self-assessment - an opportunity for student teams to self-assess the usefulness of the model, 4) model documentation - a procedure/product description, 5) model shareable and reusable - shareable and reusable for similar purposes, and 6) an effective learning prototype - a globally generalizable or modifiable procedure/prototype. These principles, developed by mathematics education researchers for middle school classrooms [12], were adapted for engineering courses and hold promise for instruction in other math and science rich contexts.

\section{Project Objectives}

This research project has three major objectives: curriculum development, teacher professional development, and student development. The three objectives are discussed below.

\section{Objective 1: Curriculum Development}

Four open-ended, integrated, culturally relevant, and real-world learning activities are being designed that focus on major societal challenges using agricultural life sciences as a context. To ensure cultural and career relevance each MEA is communicated to the societal challenges relevant to STEM careers and the local community. Societal challenges include health, energy, environment, and food., which operationally define agricultural life science and engineering. The CR MEA lessons will begin with topic related readings to introduce students to the content of the MEA. All MEA readings are based on current events and research. Readings are distributed in the form of newspaper articles, journal articles, and books. Community and career connections are facilitated by having students interact with STEM community, industry and university partners, such as, urban farmers, engineers, food scientists, horticulturalist, and researchers. As students engage with diverse community partners they will be exposed to and learn about various careers in STEM. The development of the MEA curriculum is guided by content experts to ensure that the curriculum is culturally relevant, connects with the community, aligns with state content standards, and is developmentally appropriate for middle school students.

\section{Objective 2: Teacher Professional Development}

Teacher professional development (TPD) on the use of CR MEAs is conducted for seven teachers in grades four through six. The TPD is designed to focus on increasing teachers' knowledge, skill and confidence in using an instructional method that is math and science rich and culturally and community relevant. The TPD is designed to encourage teachers' collaboration in planning, teaching, observing, revising, and sharing lessons learned from the implemented CR MEAs. 


\section{Objective 3: Student Development}

Student development is achieved through community engagement, which occurs through the CR MEA, community engagement, and mentoring. The CR MEAs require students to work closely with community, industry, and university partners to explore solutions to real-world communitybased problems. This direct interaction with professionals working in the local community provide students opportunities to learn about STEM careers, thus enhancing their level of career exploration. Currently, $4^{\text {th }}, 5^{\text {th }}$, and $6^{\text {th }}$ grade student teams from our partner school are working on a Soccer Ball MEA as an introduction to an MEA activity. Student teams are engaged in learning about soccer ball geometrics, production, and social issues such as child labor laws. Recently, students had an opportunity to meet one of our engineering partners from a local engineering plant. The engineer engaged students in manufacturing STEM related careers, community connections, and the engineering design process. Our engineering partner also shared real-world problems with the students, which provided students with examples of model-eliciting problems.

\section{Methodology}

A design-based research (DBR) approach is employed, since this study entails designing a novel educational intervention (i.e., CR MEAs) through iterative cycles of testing and researchinformed revisions. Our primary collaborating partner is a free, open-enrollment, public school located in an urban community in the Midwestern part of the country. The study population consists of students in grades four through six. There are 141 students enrolled in grades four through six. The demographic of the school population consists of 70\% African American/Black, 13.6\% Hispanic/Latinos, 10.7\% White/Caucasian, 0.9\% Asian, and 5\% Multiracial. Of the population, $73.6 \%$ of students are eligible for free or reduced-cost lunch, while $27.4 \%$ pay for lunch. Furthermore, there are seven teacher participants. The seven teachers consist of six grade level teachers and one special education teacher. Of the seven teachers, six of them are Caucasian/White and one is African American/Black. Other participants comprise of content experts and community and industry partners, such as STEM professionals, who work within the business and industry sectors. These professionals are selected based on the context of the CR MEA problems, as well as those who reflect a more culturally relevant perspective for the student population and as part of the MEA.

\section{Data Sources}

To address the research objectives previously identified multiple forms of data, pre- and postsurveys completed by students, student focus groups, teacher interviews, classroom observations, and community partners and evaluators' feedback is collected. More specifically, the first research objective, focusing on curriculum development entail data collected from community partner feedback on CR MEAs, student data associated with MEAs, teacher data from teacher interviews, and researcher data from CR MEAs developmental field notes. Data sources for the second objective, teacher professional development includes teacher professional development evaluation questionnaires, classroom observations, and teacher interviews. Finally, the third objective focusing on student development measures from pre- and post- surveys explore students' intrinsic motivation, science and math content knowledge, career interests, and self-efficacy. In addition, student interviews and student work associated with MEAs also assist to corroborate objective one and three. Data is collected over the duration of the project.

\section{Anticipated Results}

The anticipated results of this research project will be four field-tested CR MEAs that can be implemented to foster students' career exploration, STEM learning, and community engagement. These theories will contribute to our understanding of how community issues can be used as the context for mathematically rich authentic problems that enhance and develop students' level of community engagement, career exploration, STEM knowledge, literacy, and motivate students to 
pursue STEM disciplines.

\section{Acknowledgements}

The authors gratefully acknowledge the participants in this study, including project evaluators, community partners and content experts. Also, this material is based upon work supported by the National Science Foundation under Grant No. 1513256. Any opinions, findings, and conclusions or recommendations expressed in this material are those of the author(s) and do not necessarily reflect the views of the National Science Foundation. 